\title{
Estimation of titers of antibody against Pasteurella multocida in cattle vaccinated with haemorrhagic septicemia alum precipitated vaccine
}

\author{
Sabia Qureshi and Hari Mohan Saxena \\ Department of Veterinary Microbiology, \\ College of Veterinary Science, Guru Angad Dev Veterinary and Animal Sciences University (GADVASU), Ludhiana, India. \\ Corresponding author: Hari Mohan Saxena, email: hmsaxena@yahoo.com \\ Received: 17-01-2014, Revised: 09-03-2014, Accepted: 11-03-2014, Published online: 10-04-2014
}

doi: 10.14202 /vetworld.2014.224-228

How to cite this article: Qureshi S and Saxena HM (2014) Estimation of titers of antibody against Pasteurella multocida in cattle vaccinated with haemorrhagic septicemia alum precipitated vaccine, Veterinary World 7(4): 224-228.

\begin{abstract}
Aim: The present study was carried out in 100 cattle to assess the antibody response to Haemorrhagic Septicaemia alum precipitated vaccine by Microtiter Agglutination Test (MAT), Indirect Haemaaglutination Assay (IHA) and Monoclonal Antibody based Indirect Enzyme Linked Immunosorbent Assay (ELISA).

Materials and Methods: One hundred cattle from a local gaushala of Ludhiana were vaccinated with alum precipitated Haemorrhagic Septicaemia vaccine. Serum was collected at 0, 42, 84 and 128 days post immunization and antibody titers at different stages were estimated by MAT, IHA and ELISA.

Results: The animals exhibited the classical pattern of humoral immune response with gradual increase and achievement of peak antibody titers plateau by 42DPI and gradual decline by 128 DPI. The IHA titers in cattle were significantly higher $(\mathrm{P}<0.05)$ at 42 days post immunization than the corresponding MAT titers on the same day. ELISA titers were significantly higher $(\mathrm{P}<0.05)$ than MAT and IHA titers at 42 DPI. IHA was found to be more sensitive than MAT, and the titers were higher by ELISA than by MAT and IHA throughout the observation period.
\end{abstract}

Conclusion: The results indicate that animals vaccinated with commercial alum precipitated HS vaccine could not develop and sustain adequate levels of antibody for long duration.

Keywords: antibody titers, haemorrhagic septicaemia, Indirect Haemaaglutination Assay, Pasteurella multocida.

\section{Introduction}

Pasteurella multocida, a commensal of digestive and respiratory tracts of warm-blooded animals, causes disease in animals (bovines, porcines, rabbits, and poultry) weakened by stresses such as viral infections, heat, cold or humidity with aerosol transmission of infection between animals [1]. Haemorrhagic Septicaemia (HS) is an acute, fatal septicaemic disease of cattle and buffaloes caused by the bacterium Pasteurella multocida and occur as a catastrophic epizootic in many Asian and African countries resulting in high mortality and morbidity. Serotypes B: 2 and E: 2 of $P$. multocida are associated with hemorrhagic septicaemia in cattle and buffaloes in Asia and Central Africa respectively [2]. The interactions between host factors and certain specific bacterial virulence factors, like lipopolysaccharides (LPS), capsule, outer membrane proteins (OMP), fimbrial protein etc are responsible for the pathogenesis of the disease [3].

In India, HS has been identified as number one killer disease of bacterial origin among cattle and buffaloes. In a retrospective analysis of disease occurrence in cattle and buffaloes in India during the years 19741986, it was found that HS was responsible for the highest mortality and the second highest morbidity rate

Copyright: The authors. This article is an open access article licensed under the terms of the Creative Commons Attribution License (http://creativecommons.org/licenses/by/2.0) which permits unrestricted use, distribution and reproduction in any medium, provided the work is properly cited. compared to foot and mouth disease, rinderpest, anthrax and black quarter, respectively [4]. The estimated annual economic losses in India due to Pasteurella multocida infections alone were found to be to the tune of Rs. 228 millions [5].

Humoral immunity plays an important role in protection against the disease. Vaccination has a greater effect in controlling mortality in HS than any other measure [6]. The vaccines in use against HS include broth bacterins, alum precipitated, aluminium hydroxide gel and oil adjuvant vaccines [7]. The most widely used vaccines in Asia being the whole cell formalin killed $P$. multocida $\mathrm{P}_{52}$ bacterin precipitated with alum or emulsified in aluminium hydroxide gel. The alum precipitated and the aluminium hydroxide gel vaccines are reported to confer immunity for four to six months. Oil adjuvant vaccine that imparts higher level of immunity (up to 1 year) poses difficulty in injecting owing to its viscous nature and it induces inflammation at the site of injection making it unpopular among the field users [8]. Although, vaccination against HS in endemic areas with currently available vaccines is conducted regularly, outbreaks still occur emphasizing the need for improving the immunogenicity of the currently available vaccine preparations [9]. Microtiter Agglutination Test (MAT), Indirect Haemaaglutination Assay (IHA) and Enzyme Linked Immunosorbent Assay (ELISA) are usually employed to detect serum antibody levels in immunized 
animals. In the present study, antibody titers of cattle to the widely used alum precipitated HS vaccine were assessed through MAT, IHA and ELISA techniques and compared for determining the efficacy of the vaccine in inducing protective immunity.

\section{Materials and Methods}

Ethical approval: The animal experimentation was approved by the Institutional Animal Ethics Committee.

One hundred adult cattle from a local gaushala (cow shelter) of Ludhiana were included in the study. Zebus as well as cross bred of zebu and Jersey/Holstein cattle were present in the population studied. The animals included both male and female cattle which were in production or non-producers. The average age of the animals was 3 years. The animals were apparently healthy and reported to be vaccinated and dewormed annually. The animals were administered 5 $\mathrm{ml}$ of alum precipitated HS vaccine through subcutaneous route. All the animals were bled prior to vaccination and blood samples were collected at 0, 42, 84 and 128 days post immunization (DPI). Serum samples were subjected to analysis by MAT, IHA and ELISA to measure antibody titers in response to the vaccine.

Preparation of whole cell killed antigen: The whole cell killed antigen was prepared from $P$. multocida $(\mathrm{B}: 2)$ vaccine strain $\mathrm{P}_{52}$. The organisms were grown overnight on BHI agar in Roux flasks, and the bacterial cells were harvested in normal saline solution (NSS). The purity of the culture was tested by Gram's staining. The bacteria were killed by adding formalin at a final concentration of $0.3 \%$ and incubated at room temperature overnight. The sterility of the suspension was tested by inoculation of $1 \mathrm{ml}$ suspension on to the blood agar on which no growth was observed. The cell suspension was centrifuged at $1000 x \mathrm{x}$ for 15 minutes and subjected to three washings with NSS. The bacterial sediment was suspended in NSS to match the opacity with tube no. 3 of Mac Farland opacity scale.

MAT: MAT was performed as per the standard method [10]. Serum samples were serially diluted two fold in a final volume of $100 \mu \mathrm{l} .100 \mu \mathrm{l}$ of formalin killed antigen was added to each well. Negative control contained $100 \mu \mathrm{l}$ of sterilized normal saline solution (NSS) and $100 \mu \mathrm{l}$ of the antigen. The formation of matt signified agglutination whereas button formation was indicative of a negative reaction. Titers $\left(\log _{10}\right)$ were recorded as the reciprocal of the highest dilution of the serum giving at least 50 per cent agglutination.

IHA: IHA was performed as per the method reported earlier [11] with minor modifications. A $10 \%$ (v/v) suspension of sheep RBCs was prepared in NSS and stored at $4{ }^{\circ} \mathrm{C}$. Equal volumes of glutaraldehyde solution $(1 \% \mathrm{v} / \mathrm{v}$ in NSS) and $10 \%$ washed RBC suspension were mixed and allowed to stand at $4{ }^{\circ} \mathrm{C}$ for $30 \mathrm{~min}$ with intermittent gentle stirring. The sensitized sheep RBCs (SRBCs) were given three washes in NSS to remove free gultaraldehyde. A $10 \%$ suspension of SRBCs in NSS containing $0.1 \%$ sodium azide was prepared. The gluteraldehyde fixed SRBCs (G-SRBCs) were stored at $4{ }^{\circ} \mathrm{C}$. A $10 \%$ suspension of G-SRBCs was mixed with an equal volume of PBS containing $0.005 \%$ tannic acid $(\mathrm{w} / \mathrm{v})$, and incubated at $37^{\circ} \mathrm{C}$ for $30 \mathrm{~min}$ with occasional shaking. The tanned G-SRBCs (TG-SRBCs) were pelleted and washed three times with PBS to yield a $10 \%$ suspension. The antigen prepared as described earlier was heated at $56{ }^{\circ} \mathrm{C}$ for $30 \mathrm{~min}$ in a water bath with frequent shaking. Heat treated suspension was then centrifuged at $6000 \mathrm{xg}$ for $15 \mathrm{~min}$ at $4{ }^{\circ} \mathrm{C}$. The clear supernatant was separated and stored at $-20{ }^{\circ} \mathrm{C}$. One volume of packed TG-SRBCs and 15 volumes of the antigen, approximately were mixed and incubated for 1-2 hrs at $37{ }^{\circ} \mathrm{C}$ in a water bath with frequent shaking. The sensitized cells thus prepared were washed 3 times with NSS and resuspended in chilled NSS to obtain a $1 \%$ suspension. To remove the heterophile antibodies, all the test serum samples (3 volumes) were adsorbed with packed SRBCs (1 volume) for $2 \mathrm{hr}$ at $37{ }^{\circ} \mathrm{C}$ with periodic shaking before the test proper. The RBCs were removed by centrifugation. The supernatant was collected and used for the test. Normal saline $(160 \mu \mathrm{l})$ and adsorbed serum $(40 \mu \mathrm{l})$ were added to the first well (1:5 dilution), and $100 \mu \mathrm{l}$ of NSS was added to all the other wells of a U bottom 96 well microtitre plate (Tarson). Two fold serial dilutions of serum were made. An equal volume of the $0.5 \%$ sensitized RBC suspension was added to all the wells. The plates were agitated briefly and left at room temperature for $2 \mathrm{hr}$. Appropriate antigen, $\mathrm{RBC}$ and serum controls were also incorporated in the test.

ELISA: Indirect ELISA procedure was carried out as per method described earlier [12]. The antibody titre of the serum samples was determined by monoclonal antibody (Mab) based indirect ELISA Kit prepared at the Department of Veterinary Microbiology, College of Veterinary Science, Lala Lajpat Rai University of Veterinary and Animal Sciences (LLRUVAS), Hisar, Haryana. The kit is based on indirect ELISA using outer membrane proteins of the $\mathrm{P}_{52}$ strain of the bacteria as antigen (dilution1:1000). The binding of the antibodies in serum samples with the plate bound antigen was detected by a monoclonal antibody against cattle IgG conjugated with horse radish peroxidase. Using an equation of regression, antibody titers were calculated from the intensity of color developed in a chosen single dilution of the test sera. The optical density (O.D.) was read on an ELISA Reader (Tecan) at 450nm.

Antibody titre $\left(\log _{10}\right) \mathrm{Y}=\mathrm{a}+\mathrm{bX}$

$$
=1.35+0.05 \mathrm{X}
$$

Where constant $\mathrm{a}=1.35$, constant $\mathrm{b}=0.05$, $X=$ O.D. value of a test well/ (Mean +3 S.D. value of negative controls wells).

Statistical analysis: SPSS 16 software was used for data analysis. The values were converted to $\log _{10}$ before analysis. 


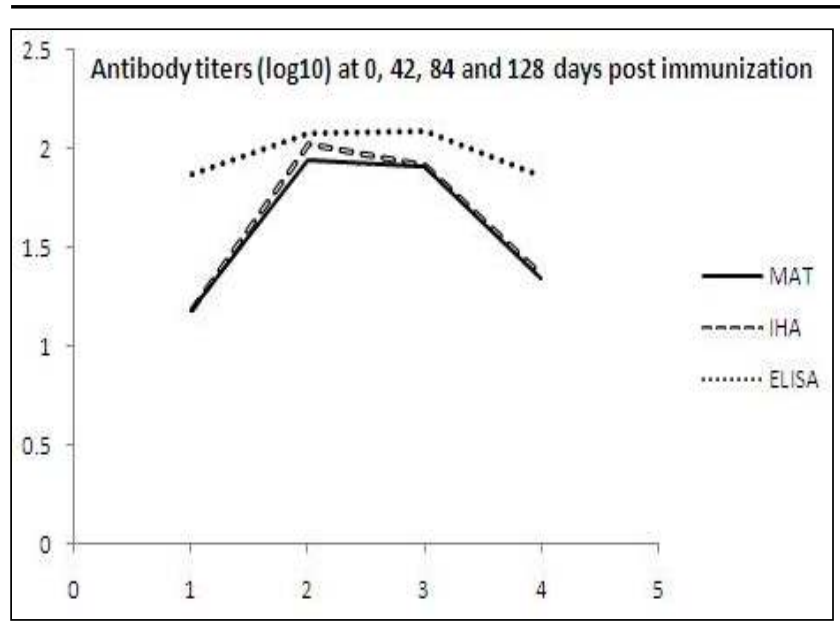

Figure-1. Antibody titers $(\log 10)$ at $0,42,84$ and 128 days post immunization.

\section{Results and Discussion}

The post vaccination antibody titers in cattle vaccinated with alum precipitated HS vaccine revealed an increase over the initial prevaccination stage, with peak antibody response being observed at $42 \mathrm{DPI}$, plateauing up to 84 DPI and gradually declining thereafter as determined by MAT, IHA and ELISA (Figure-1). The antibody titers $\left(\log _{10}\right)$ as determined by MAT, IHA and ELISA are presented in Table-1. The mean value of peak antibody titers $\left(\log _{10}\right)$ induced by vaccine in these cattle was 1.948 as measured by MAT, 2.020 by IHA and 2.076 by ELISA, respectively. However, the decline by 128 DPI to a mean $\log _{10}$ titre of 1.349 (MAT), 1.355 (IHA) and 1.862 (ELISA) indicated that the immune response generated was of low magnitude and of short duration and may not confer adequate immunity. The IHA titers in cattle were significantly higher $(\mathrm{P}<0.05)$ at 42 days post immunization than the corresponding MAT titers on the same day. Mean ELISA titers were significantly higher $(\mathrm{P}<0.05)$ than MAT and IHA titers at 42 DPI. However, MAT and IHA titers at 84 and 128 DPI did not reveal any significant difference. ELISA titers were significantly higher than IHA and MAT titers at 84 and 128 DPI, respectively. The results of our study are in concurrence with the findings of other workers who have reported IHA to be more sensitive than MAT for studying antibody response in haemorrhagic septicemia.

In the present study IHA was found to be more sensitive than MAT in assessing the antibody levels. The different titers observed in the same animals by agglutination assays (MAT/IHA) and ELISA can be reconciled with the fact that these two assays target antigens of different nature i.e. agglutination assays are directed towards particulate antigen whereas ELISA detects immune response to soluble antigens. ELISA is generally used to detect IgG antibodies [13], while IHA is used to detect the major immunoglobulin fraction IgM induced in response to such vaccination [14].

In a comparative study of alum adsorbed HS vaccine, $P$. multocida anti-idiotypic vaccine prepared
Table-1. Mean antibody titers in cattle vaccinated with HS alum precipitated vaccine by MAT, IHA and ELISA $(n=100)$

\begin{tabular}{|c|c|c|c|}
\hline \multirow{2}{*}{$\begin{array}{l}\text { Days post } \\
\text { immunization }\end{array}$} & \multicolumn{3}{|c|}{ Mean* antibody titers } \\
\hline & MAT & $\mathrm{IHA}$ & ELISA \\
\hline 0 & $1.184 \pm 0.022^{\mathrm{a}}$ & $1.184 \pm 0.022^{\mathrm{a}}$ & $1.870 \pm 0.035^{\mathrm{a}}$ \\
\hline 42 & $1.948 \pm 0.030^{\mathrm{C}}$ & $2.020 \pm 0.028^{d}$ & $2.076 \pm 0.033^{b}$ \\
\hline 84 & $1.918 \pm 0.029^{c}$ & $1.915 \pm 0.027^{\mathrm{c}}$ & $2.088 \pm 0.030^{b}$ \\
\hline 128 & $1.349 \pm 0.031^{b}$ & $1.355 \pm 0.031^{b}$ & $1.862 \pm 0.029^{\mathrm{a}}$ \\
\hline
\end{tabular}

Values with different letters in superscript differ significantly at $\mathrm{P}<0.05$.

from OMPs and bacterin supplemented with $10 \%$ OMPs, the mean IHA titers 21 days post vaccination were $27.9,168.9$ and 42.4 , respectively [15]. It was concluded that subunit or whole bacterin based vaccines had less immunogenic potential in comparison to antiidiotypic vaccine prepared against $P$. multocida $\mathrm{B}: 2$.

It has earlier been reported by Venkatesh et al [16] that maximum antibody titers $\left(\log _{10}\right)$ of 2.46 were observed at 12 weeks PI which decreased to 1.52 at 24 weeks PI in bovines vaccinated with alum precipitated vaccine thus necessitating vaccination at six monthly intervals. In a study conducted on American bison, IHA was observed to be the most practical test among the four serological tests in the sero-diagnosis of haemorrhagic septicaemia [17].

In a study conducted by Sangwan V. P. [18] on buffaloes, administered alum precipitated vaccine, antibody levels were found to be high up to 84 days post vaccination after which they declined. In an earlier study, the mean antibody titers $\left(\log _{10}\right)$ by ELISA four months post vaccination in buffaloes vaccinated with aluminium hydroxide gel precipitated $\mathrm{HS}$ vaccine were found to be $2.22 \pm 0.06,2.09 \pm 0.02,3.46 \pm 0.08$ and 2.14 \pm 0.03 , respectively, and were claimed to be protective, whereas at six months post vaccination they were found to be marginally protective [19].

It has been reported by Altaf et al [20] that peak mean antibody titre (40.3 IHA units) was achieved on $35^{\text {th }}$ day post immunization with alum precipitated HS vaccine whereas in bivalent FMD-HS vaccine, the peak level of antibody titre was detected on 48 days post priming which persisted for a longer time than the monovalent alum precipitated $\mathrm{HS}$ vaccine.

The mean antibody titers of thirty pregnant Sahiwal cows vaccinated with alum precipitated formalin killed bacterin 15 days prior to parturition and after parturition were 213 and 182, respectively by IHA [21].

Humoral immune response in mice against $\mathrm{P}$. multocida vaccine grown in presence of serum was compared using ELISA and IHA. The highest antibody titers as measured by IHA and ELISA were observed on $7,14,45$, and 75 , DPI. No significant difference in the 
mean IHA titre and mean ELISA titre of different groups was reported [22]. In a study conducted by Shaveta H. [23], on cattle and buffaloes vaccinated with alum precipitated HS vaccine, the mean antibody titre $\left(\log _{10}\right)$ of 1.47 was achieved at 120 days post vaccination as determined by monoclonal antibody based ELISA. It has long been held that antibody titers measured by ELISA are better representatives of protection level achieved after direct challenge because in ELISA, only IgG titers can be determined. On the other hand, IHA and agglutination tests will not prove to be as dependable as ELISA because these tests measure the overall IgM and IgG response.

Our results support the notion that the widely used alum precipitated HS vaccine does not provide long duration of immunity as titers waned 128 days post vaccination. It has been reported earlier that available vaccines suffer from demerits like alum precipitated vaccines induce short term immunity, oil adjuvant vaccine poses difficulty in administration, and genetically modified mutant may revert to virulent form, thereby necessitating the development of an improved vaccine. Several structural components of $P$. multocida like capsules, OMPs, iron regulated outer membrane proteins (IROMPs) and DNA vaccine are being identified as potential targets for development of safe and efficacious vaccine in future $[24,25]$.

\section{Conclusion}

Antibody response to HS alum precipitated vaccine was found to peak (MAT- 1.94, IHA- 2.02) at 42 DPI by agglutination tests and at 84 DPI by ELISA (2.08) with gradual decline by 128 days post immunization. IHA was found to be better than MAT in estimation of antibody titers. ELISA titers were significantly higher $(\mathrm{P}<0.05)$ than MAT and IHA titers at 42,84 and 128 DPI, respectively.

\section{Authors' contributions}

SQ did the experimentation and statistical analysis; HMS was the Principal Investigator of the project which funded the study. He planned the study, analyzed the results and prepared the manuscript.

\section{Acknowledgements}

The authors gratefully acknowledge the help rendered in the study by Dr. Arvind Kumar, Department of Veterinary Microbiology, College of Veterinary Science, LLRUVAS, Hisar, Dr. Darshan Singh, Govind Gaudham, Gaushala, Ludhiana and Dr. N K Talwar, and Dr. Jagdeep Singh, Punjab Veterinary Vaccine Institute, Ludhiana. The financial assistance provided by University Grant Commission, India for the project is duly acknowledged.

\section{Competing interests}

The authors declare that they have no competing interests.

\section{References}

1. Kumar, A. A., Shivachandra, S. B., Biswas, A., Singh, V. P. and Srivastava, S.K. (2004) Prevalent serotypes of
Pasteurella multocida isolated from different animal and avian species in India. Vet. Res. Commun., 28: 657-667.

2. Benkirane, A. and De Alwis, M.C.L. (2002) Haemorrhagic septicaemia, its significance, prevention and control in Asia. Vet. Med. Czech., 47: 234-240.

3. Harper M, Boyce JD, Adler B. (2006) Pasteurella multocida pathogenesis: 125 years after Pasteur. FEMS Microbiol Lett. 265(1):1-10.

4. Dutta, J., Rathore, B.S., Mullick, S. G., Singh, R. and Sharma, G. C. (1990) Epidemiological studies on occurrence of haemorrhagic septicaemia in India. Ind. Vet. J., 67(10): 893-899.

5. Singh, V. P, Sinha, D. K., Gupta, S. K. and Chauhan, R. S. (2008) Prevalence of H.S in India. Proceedings of V Annual Scientist Meet on Haemorrhagic Septecaemia, Guwahati. Assam. September 5-6th.

6. Plotkin, S.A. (2009) Vaccine: The Fourth Century. Clin. Vaccine Immunol., 16(12):1709-1719.

7. Confer, A. W. (1993) Immunogens of Pasteurella. Vet. Microbiol., 37: 353-68.

8. Verma, R. and Jaiswal, T. N. (1997) Protection, humoral and cell mediated immune responses in calves immunized with multiple emulsion haemorrhagic septicaemia vaccine. Vaccine., 15: 1254-60.

9. Shivchandra, S. B., Viswas, K.N. and Kumar. A.A. (2011) A review of haemorrhagic septicemia in cattle and buffalo. Anim. Hlth Res. Rev., 12:67-82.

10. Williams, J. E. and Whitemore, A. D. (1971) Serological diagnosis of pullorum disease with the microagglutination system. Appl.Microbiol., 21:392-99.

11. Sawada, T., Rimler, R. B. and Rhoades, K. R. (1982) Indirect haemagglutination test that uses glutaraldehyde fixed sheep erythrocytes sensitized with extract antigen for detection of Pasteurella antibody. J. Clin. Microbiol., 15 (5): 752-56.

12. Engvall, E. and Pearlmann, P. (1972) Enzyme linked immunosrbent assay, ELISA. Quantitation of specific antibodies by enzyme-labeled anti-immunoglobulin in antigen coated tubes. J. Immunol., 109:129-135.

13. Long, G. Y., Liang, H. Z. and Liu, J. S. (1986) Immunization of rabbits against pasteurellosis. Chinese J. Vet. Sci.Technol., 2:3-7.

14. Manning, P.J., Digiacomo, R.F. and Delong, D. (1989) Pasteurellosis in laboratory animals. In Pasteurella and Pasteurellosis. Academic Press., 283.

15. Arif, J., Rehman, S., Arshad, M. and Akhter, P. (2013) Immunopotentiation of outer membrane protein through anti-idiotype Pasteurella multocida vaccine in rabbits. Biol., 41(6):339-334.

16. Venkatesh, M. D., Girdhar, P., Ananth, M. and Murthy, B. K. (1991) Immune response in cattle to alum-precipitated haemorrhagic septicaemia vaccines. Ind. Vet. J., 68: 812817.

17. Heddleston, K.L. and Gallagher, J. E. (1969) Septicemic pasteurellosis (hemorrhagic septicemia) in the American bison: a serologic survey. Bull. Wild Life Dis. Assoc., 5: 206-207.

18. Sangwan, V. P. (1999) Studies on outer membrane protein(s) of Pasteurella multocida for monitoring protective immunity. M.V.Sc. thesis submitted to CCS Haryana Agricultural University, Hisar.

19. Kumari,L., Kumar, S., Kumar, A., Mahajan, N.K., Pander, B.L. Khokhar, R.S (2007) Seromontiroing of cattle and buffaloes vaccinated against haemorrhagic septicaemia using monoclonal antibody based indirect ELISA. $J$. Immunol. Immunopathol., 9(1\&2): 67-70.

20. Altaf, I., Siddique,M., Muhammad, K., Irshad, M., Khan, M.Z., Anjum, A.A. and Kamran, M. (2011) Antibody response of rabbits to combined hemorrhagic septicaemia and foot \& mouth disease virus vaccine. J. Anim. Plant Sci., 22(2): 501-504.

21. Mahmood, A.K., Sheikh, M.A., Akhtar,S., Nabi, G. and Rashid, H.B. (2007) Duration of maternally derived 
antibodies against Pasteurella multocida in cow calves. Pak.Vet.J., 27(2): 92-94.

22. Somarajana S.R., Chaturvedi, V.K., Gupta, P.K., Pandey, K.D., Kumara,B., Sridevi, R. and Nair, B.C. (2006) Immunogenicity of vaccines made from Pasteurella multocida grown in the presence of serum. Ind. J. Comp. Microbiol. Immunol. Infect. Dis., 27(1):16-8.

23. Shaveta, H. (2010) Studies on B lymphocyte response in bovines vaccinated against Haemorrhagic Septicaemia.
M.V.Sc. thesis submitted to Guru Angad Dev Veterinary and Animal Science University, Ludhiana.

24. Kharab, S. and Charan S (2010) Immunogenicity of ironregulated outer membrane proteins of Pasteurella multocida B:2 in mice model. Ind. J. Exp. Biol. 48(12):1181-1187.

25. Singh, S., Singh, V.P., Cheema, P.S., Sandey, M., Ranjan, R., Gupta, S.K. and Sharma, B. (2011) Immune response to DNA vaccine expressing transferrin binding protein a gene of Pasteurella multocida. Braz. J. Microbiol., 42(2):750-60.

$* * * * * * * *$ 